\title{
Silicon-On-Insulator (SOI) Devices and Mixed- Signal Circuits for Extreme Temperature Applications
}

\author{
Richard Patterson \\ NASA Glenn Research Center \\ Richard.L.Patterson@nasa.gov \\ Ahmad Hammoud \\ ASRC Aerospace Corporation \\ ahmad.hammoud@grc.nasa.gov
}

\author{
Malik Elbuluk \\ University of Akron \\ melbuluk@uakron.edu
}

\begin{abstract}
Electronic systems in planetary exploration missions and in aerospace applications are expected to encounter extreme temperatures and wide thermal swings in their operational environments. Electronics designed for such applications must, therefore, be able to withstand exposure to extreme temperatures and to perform properly for the duration of the missions.

Electronic parts based on silicon-on-insulator (SOI) technology are known, based on device structure, to provide faster switching, consume less power, and offer better radiation-tolerance compared to their silicon counterparts. They also exhibit reduced current leakage and are often tailored for high temperature operation. However, little is known about their performance at low temperature. The performance of several SOI devices and mixed-signal circuits was determined under extreme temperatures, cold-restart, and thermal cycling. The investigations were carried out to establish a baseline on the functionality and to determine suitability of these devices for use in space exploration missions under extreme temperatures. The experimental results obtained on selected SOI devices are presented and discussed in this paper.
\end{abstract}

\section{INTRODUCTION}

Electronics in space exploration missions and in aerospace are expected to encounter extreme temperatures and wide thermal swings. Such missions include planetary surface exploration and deep space probes (hot and/or cold temperature), jet engine distributed control (hot), and NASA James Webb Space Telescope and space-based infrared satellite systems (cold). Besides deep space, cold temperatures are encountered in terrestrial applications such as magnetic levitation transportation systems, medical diagnostics, cryogenic instrumentation, and superconducting magnetic energy storage systems. Aircraft engines, power generation facilities, automotives, downhole instruments, and all-electric boat and aircraft, on the other hand, require high temperature electronics.
Electronics capable of extreme temperature operation would eliminate thermal control elements and associated structures for proper ambient operation. This would lead to many benefits including decreased system mass and size, simplified design complexity, and reduced power requirements. In addition, reduced development time and launch costs, as well as extended mission operations for longer observation or exploration time can be achieved.

To address the needs for extreme temperature electronics, research efforts exist at the NASA Glenn Research Center to develop and evaluate electronics for extreme temperature operations, and to establish their reliability for use in space applications. This paper reports on the results obtained on the performance of selected silicon-on-insulator (SOI) devices and circuits that were evaluated under extreme temperature operation and thermal cycling; conditions that are typical of the space environment.

\section{SOI POWER MOSFETS}

A high temperature N-channel power FET, which is based on SOI technology, was evaluated for cryogenic use. The MOSFET device operating temperature is specified in the range of $-55^{\circ} \mathrm{C}$ to $+225{ }^{\circ} \mathrm{C}$ and is a member of a high temperature product line [1]. A control device, i.e. a standard "non-SOI" power FET [2], was also subjected to the same temperature testing and its results were used for comparison to the SOI device. Two samples of each device were evaluated. Both samples of each type of device have shown exact behavior in their characteristics with temperature, therefore, data pertaining to only one of these devices will be presented.

Performance characterization of the MOSFET devices was obtained in terms of their gate threshold voltage (VGS(th)), drain-to-source on-state resistance $(\operatorname{RDS}(\mathrm{on}))$, and drain current (ID) versus drain-to-source voltage (VDS) family 
curves at various gate voltages (VGS). Figure 1 shows the gate threshold voltage (VGS(th)) versus temperature for the two devices. The gate threshold voltage for each device was measured at very small values of drain currents. A drain current of $250 \mu \mathrm{A}$ and $100 \mu \mathrm{A}$ was set for the standard MOSFET and the SOI, respectively, according to their manufacturer's specifications. As seen from Figure 1, both devices exhibit an increase in gate threshold voltage with decreasing temperature. The standard MOSFET, which has a maximum specified gate voltage of $20 \mathrm{~V}$, exhibits a gate threshold voltage in the range of $3.03 \mathrm{~V}$ to $3.92 \mathrm{~V}$ from 20 ${ }^{\circ} \mathrm{C}$ to $-190{ }^{\circ} \mathrm{C}$. This corresponds to a normalized gate threshold voltage (VGS(th)/ VGS (max)) between 0.152 and 0.196. The SOI MOSFET, which has a maximum specified gate voltage of $10 \mathrm{~V}$, displays a gate threshold voltage in the range of $1.64 \mathrm{~V}$ to $2.21 \mathrm{~V}$ from $20^{\circ} \mathrm{C}$ to $-190{ }^{\circ} \mathrm{C}$. This corresponds to a normalized gate threshold voltage range of 0.164 to 0.221 . In general, both devices show comparable changes in gate threshold voltage with change in temperature.

Figure 2 shows the drain-to-source on-state resistance (RDS(on)) versus temperature for the two devices. Onstate resistance values were obtained at a drain current of $0.6 \mathrm{~A}$ and a gate voltage of $8 \mathrm{~V}$ for the Standard MOSFET, and at a drain current of $0.6 \mathrm{~A}$ and a gate voltage of $5 \mathrm{~V}$ for the SOI MOSFET. As can be seen from Figure 2, both devices exhibit a decrease in on-state resistance with decreasing temperature down to $-175{ }^{\circ} \mathrm{C}$. Beyond this temperature, the on-state resistance for both devices, however, begins to increase as temperature is decreased further. At any given temperature, the SOI has a slightly higher on-state resistance than the standard MOSFET.

Figure 3 shows the drain current (ID) versus drain-to-source voltage (VDS) at various gate voltages (VGS) of the standard MOSFET at room temperature $\left(20^{\circ} \mathrm{C}\right)$ and at -190 ${ }^{\circ} \mathrm{C}$. The range of the gate voltage utilized was from $3.0 \mathrm{~V}$ to $8.0 \mathrm{~V}$. Note that no output is obtained with VGS equal to $3.0 \mathrm{~V}$, which is below the gate threshold voltage of 3.03 volts. Two temperature-induced effects can be noted in the output characteristics of the device with change in the test temperature. The first is the downward shift of the VGS curves due to the increase in the gate threshold voltage with decreasing temperature. This trend is more obvious as illustrated for $\mathrm{VGS}=5.0 \mathrm{~V}$ or less. There is also a leftward shift of the VGS curves, especially at VGS $\geq 6.0 \mathrm{~V}$. This shift is primarily due to the decrease in the on-state resistance with decreasing temperature. The same characteristics for the SOI MOSFET at room temperature $\left(20{ }^{\circ} \mathrm{C}\right)$ and at $-190{ }^{\circ} \mathrm{C}$ are shown in Figure 4. Gate voltages (VGS) utilized in this test were between $1.5 \mathrm{~V}$ and $6.0 \mathrm{~V}$. Once again, a VGS level exceeding the gate threshold voltage value must be applied for the device to produce any output. Similar to its standard counterpart, the SOI device exhibits changes in its characteristics with temperature. These changes, which are reflected by the shift and steepness of the family curves, are attributed to the increase in the gate threshold voltage and the decrease in the on-state resistance as temperature is decreased.

\section{MOSFET DRIVER CIRCUIT}

An SOI bridge driver circuit, designed for driving MOSFETs was evaluated under wide temperature range. The chip has an internal adjustable oscillator, and can be also operated via external oscillator control [3]. The driver chip was tested in a circuit constructed to power a resistive load via MOSFET switches in a full bridge setup, as shown in Figure 5, and its operation was investigated as a function of temperature between $-195^{\circ} \mathrm{C}$ and $+85^{\circ} \mathrm{C}$.

Waveforms of the driver output signals GHR, GLR, GHL, and GLL obtained at $20,-195$, and $+85{ }^{\circ} \mathrm{C}$ are shown in Figure 6. It can be clearly seen that no major change or distortion was observed in the shape or magnitude of these waveforms as test temperature was changed throughout the range of $-195{ }^{\circ} \mathrm{C}$ to $+85{ }^{\circ} \mathrm{C}$. Cold-start capability of the driver chip was also investigated by allowing the device to soak at $-195{ }^{\circ} \mathrm{C}$ for at least 20 minutes without the application of electrical bias. Power was then applied to the driver circuit, and measurements were taken on the output characteristics. The driver chip was able to successfully cold-restart at $-195{ }^{\circ} \mathrm{C}$, and the results obtained were the same as those obtained earlier at that temperature, i.e. under bias.

The effects of thermal cycling under a wide temperature range on the operation of the driver IC chip were investigated by subjecting it to a total of 12 cycles between $-195{ }^{\circ} \mathrm{C}$ and $+85{ }^{\circ} \mathrm{C}$. Measurements of the investigated parameters were then taken at $+20,-195$, and $+85^{\circ} \mathrm{C}$. A comparison of the driver output signals for pre- and postcycling conditions at the test temperatures of $+20,-195$, and $+85^{\circ} \mathrm{C}$ are shown in Figures 7, 8, and 9, respectively. It is obvious that the post-cycling modulated outputs at any given test temperature were the same as those obtained prior to cycling. Therefore, it can be concluded that the extreme temperature exposure and the thermal cycling did not induce much change in the behavior of this SOI chip. This limited thermal cycling also appeared to have no effect on the structural integrity of this device as no structural deterioration or packaging damage was observed.

\section{SOI MONOLITHIC QUAD OPERATIONAL AMPLIFIER}

A monolithic quad operational amplifier using silicon-oninsulator technology process and designed for use in high temperature environments was evaluated under extreme temperatures. The ceramic-packaged chip is specified for operation between $-55{ }^{\circ} \mathrm{C}$ and $+225{ }^{\circ} \mathrm{C}$ with a $15 \mathrm{~mA}$ output current capability, and it can operate from a single or dual supply. The amplifier can be used in applications such as down-hole oil well, turbine engine control, avionics, and electric power conversion. An amplifier circuit configured in a unity gain, inverting configuration was constructed utilizing the SOI chip and a few passive components. The circuit was evaluated in the temperature range between $195{ }^{\circ} \mathrm{C}$ to $+200{ }^{\circ} \mathrm{C}$ in terms of signal gain, phase shift, and supply current. These properties were recorded at selected 
test temperatures in the frequency range of $1 \mathrm{kHz}$ to 10 MHz. Cold-restart capability, i.e. power switched on while the device was at cryogenic temperatures, was also investigated. Pre- and post-cycling measurements were performed after exposure of the circuit to a total of 10 cycles between $-195^{\circ} \mathrm{C}$ and $+200{ }^{\circ} \mathrm{C}$.

The gain and phase shift of the amplifier at various test temperatures in the frequency range of $1 \mathrm{kHz}$ to $10 \mathrm{MHz}$ is shown in Figure 10. It can be clearly seen that the gain of the amplifier remained relatively the same, regardless of the test temperature, until the test frequency of about $400 \mathrm{kHz}$ was reached. Beyond that frequency, gain rolled off as a function of temperature. This dependency was, however, slight and it seemed to occur most notably at the extreme cryogenic temperature, i.e. -150 and $-195{ }^{\circ} \mathrm{C}$. In the high temperature regime, the amplifier's gain did not exhibit much deviation from its room temperature characteristics. While the roll-off frequency $(-3 \mathrm{~dB}$ gain) at room temperature was at $850 \mathrm{kHz}$, it slightly increased to about 1 $\mathrm{MHz}$ at $+200{ }^{\circ} \mathrm{C}$, and dropped to about $500 \mathrm{kHz}$ at $-195{ }^{\circ} \mathrm{C}$. As far as the frequency is concerned, the gain began to show appreciable drop above $4 \mathrm{MHz}$. This drop in the gain at very high frequencies is typical of most operational amplifiers. The data depicted in Figure 10, thus, indicate that the amplifier circuit had operated well in the temperature range between $-195{ }^{\circ} \mathrm{C}$ and $+200{ }^{\circ} \mathrm{C}$. Similar to the gain characteristics, the phase exhibited very slight changes only at the extreme cryogenic temperatures and at frequencies above $400 \mathrm{kHz}$.

Cold-restart testing of the circuit revealed that the amplifier was able to operate properly at $-195{ }^{\circ} \mathrm{C}$ as the circuit's operational characteristics were similar to those obtained earlier at that temperature when the device was powered on. The amplifier's gain and phase obtained after thermal cycling is shown in Figure 11 as a function of frequency at the selected test temperatures of $+200,+25$, and $-195^{\circ} \mathrm{C}$. It can be clearly seen that these results were very similar to those obtained prior to cycling that are depicted in Figure

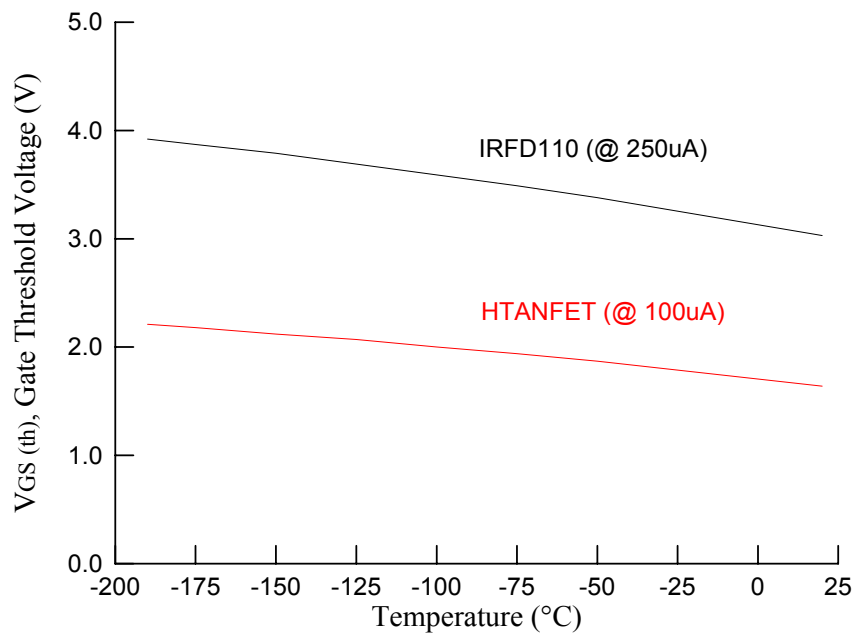

Figure 1. Gate threshold voltage for SOI and standard MOSFETs as a function of temperature.
10 and, thus, it can be concluded that the thermal cycling had no effect on the amplifier's gain or phase margin. In addition to maintaining its electrical performance with cycling, the operational amplifier chip did not suffer any deterioration or damage in its packaging due to this limited thermal cycling.

\section{CONClusions}

The performance of various silicon-on-insulator (SOI) devices was determined under extreme temperature exposure, cold-restart capability, and thermal cycling. These devices included $\mathrm{N}$-channel power field-effect transistor (FET), full-bridge driver integrated circuit chip, and a monolithic operational amplifier. Although these devices are designed for high temperature operation, not much data exist on their performance at cryogenic temperatures. Evaluation of these devices was carried out to include temperatures as low as $-195{ }^{\circ} \mathrm{C}$. All of these devices performed well throughout the test temperature range, under cold restart, and after exposure to wide temperature thermal cycling. In addition to maintaining their electrical performance, these SOI components underwent no change in their packaging due to either the extreme temperature exposure or the thermal cycling. These preliminary results suggest that such devices and circuits have good potential for use in both hot and cold temperature environments. Long-term exposure to extreme temperatures, thermal cycling, and mechanical vibrations, however, need to be addressed to establish their reliability and to better determine their suitability for use in hostile space and aerospace applications.

\section{REFERENCES}

[1] Honeywell Solid State Electronics Center, "HTANFET High Temperature N-Channel Power FET", Data Sheet 900214, Rev. D, 604.

[2] International Rectifier, "IRFD110 HEXFET Power MOSFET", Document \#90159, PD9.328K.

[3] Philips Semiconductor, "UBA2033 HF Full-bridge Driver IC", Data Sheet, Product Specification, October 8, 2002.

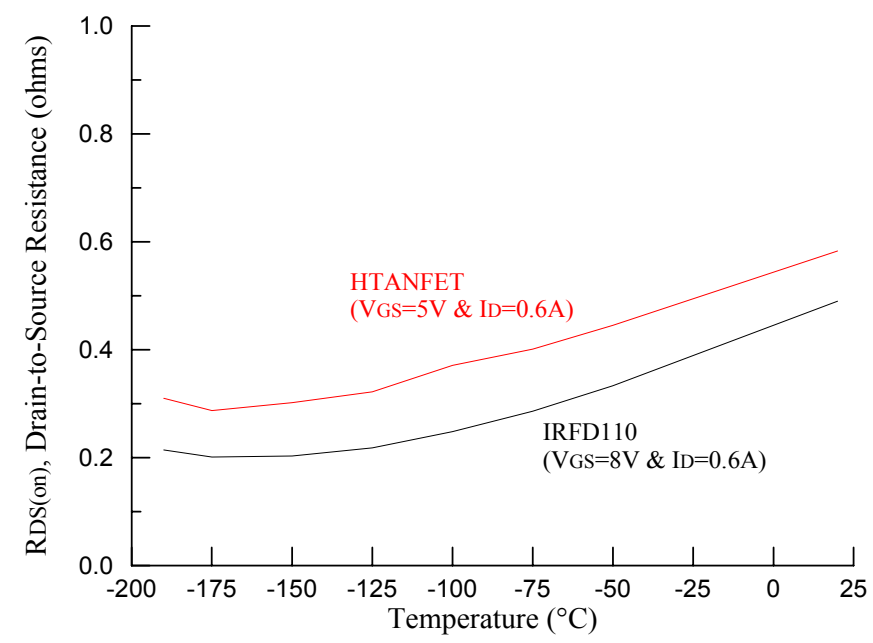

Figure 2. Drain-to-source resistance for SOI and standard MOSFETs as a function of temperature. 


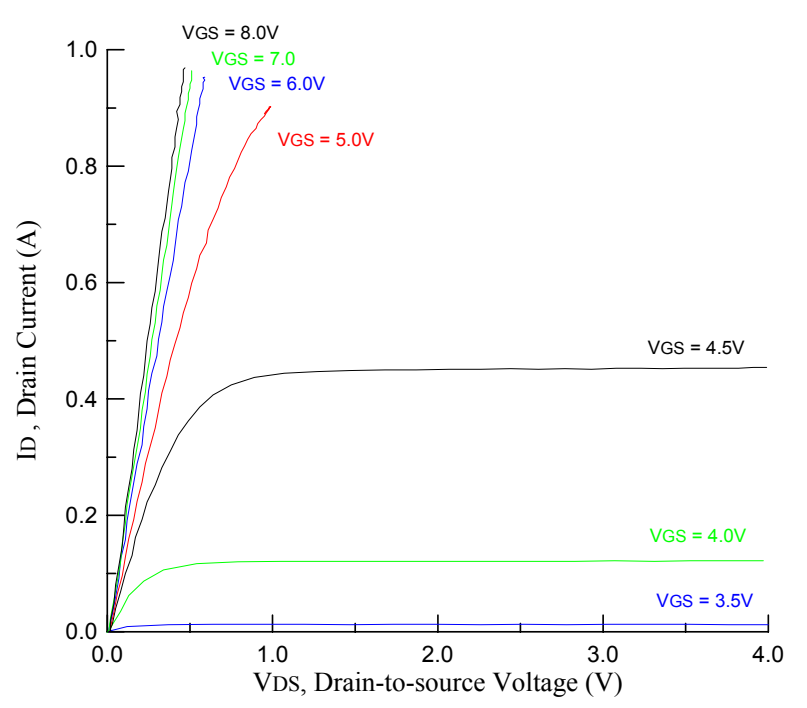

(a) at $20{ }^{\circ} \mathrm{C}$

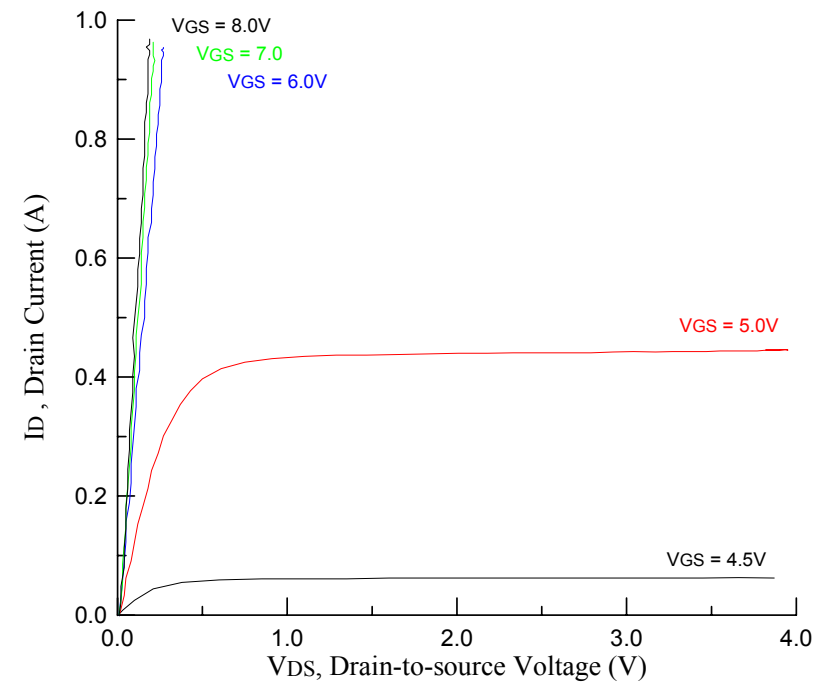

(b) at $-190^{\circ} \mathrm{C}$

Figure 3. Current/voltage characteristics of the standard MOSFET device.

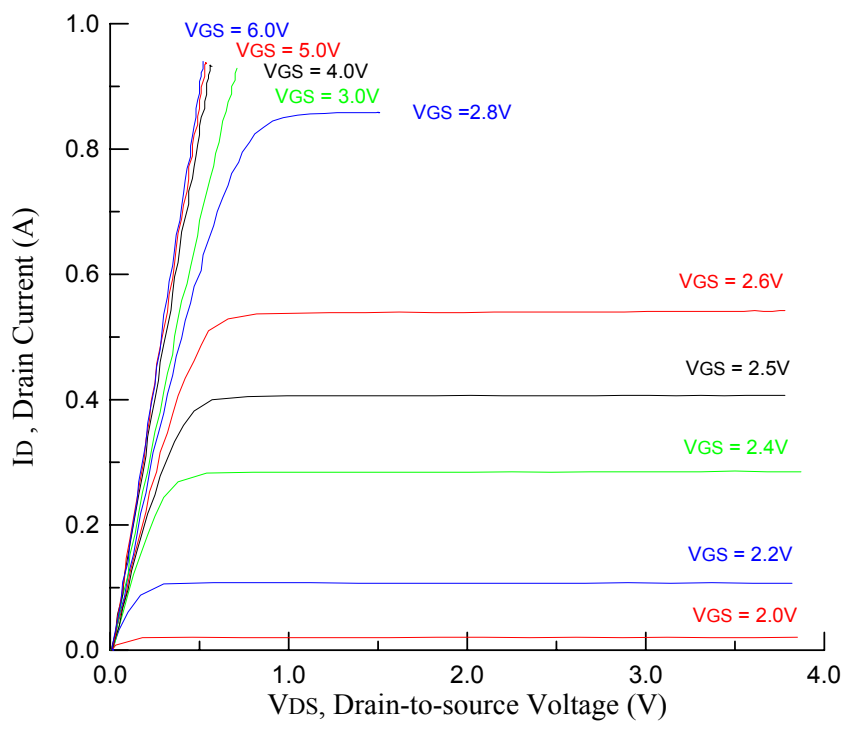

(a) at $20{ }^{\circ} \mathrm{C}$

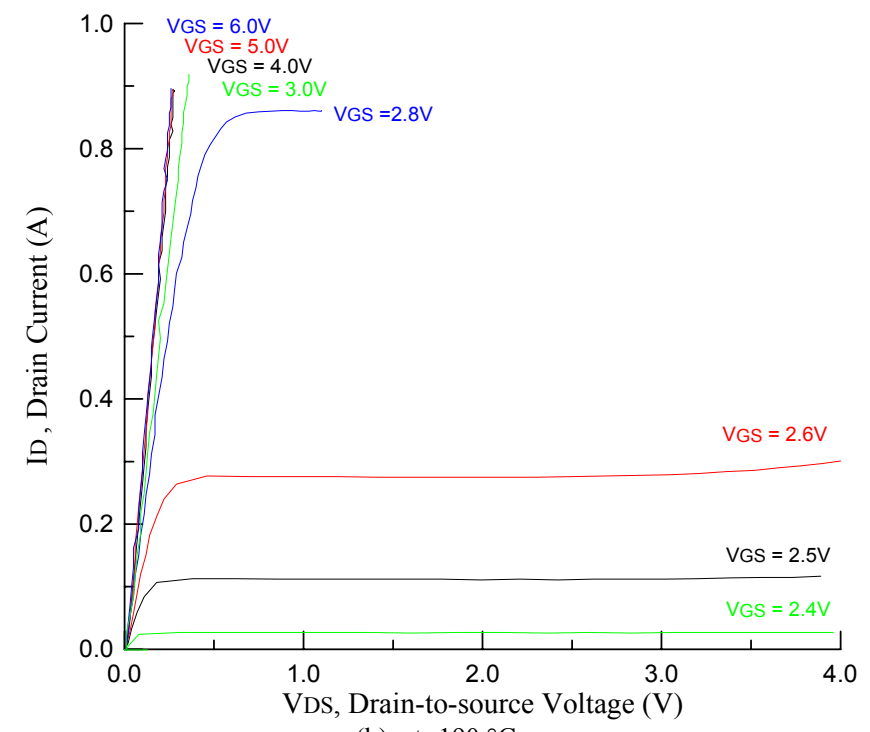

(b) at $-190{ }^{\circ} \mathrm{C}$

Figure 4. Current/voltage characteristics of the SOI MOSFET device.

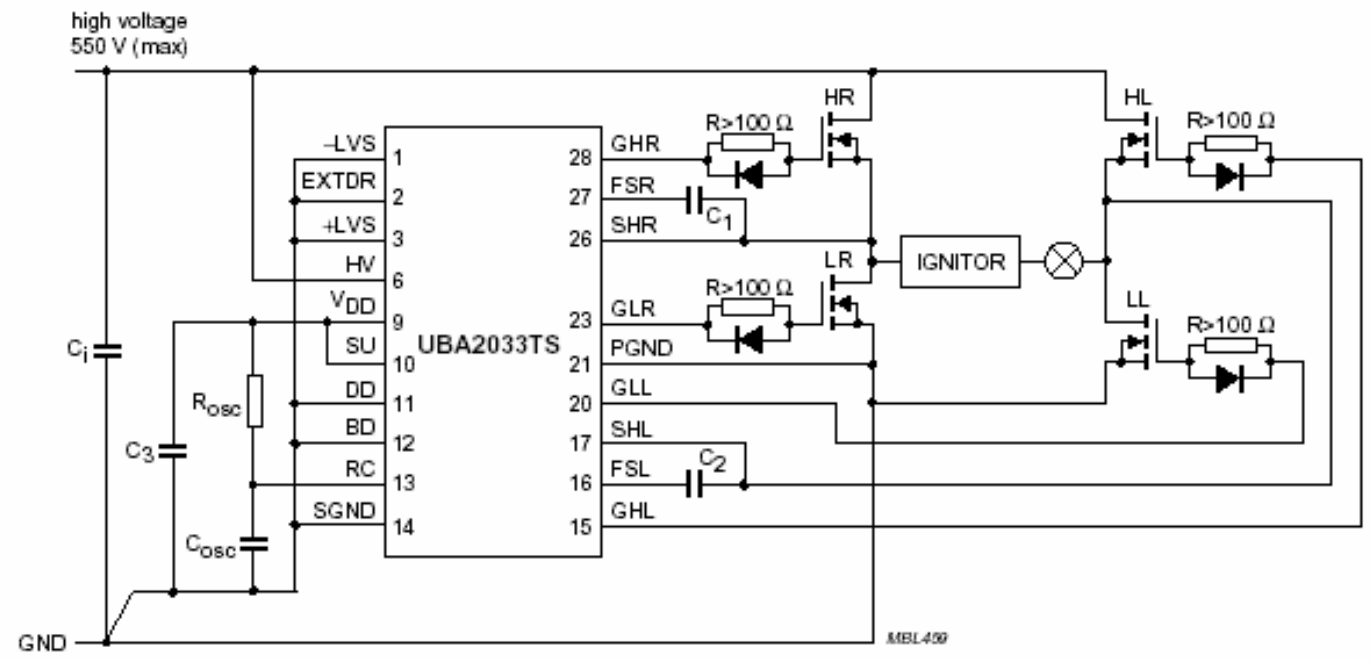

Figure 5. Schematic of circuit used in the evaluation of full bridge driver SOI IC chip [3]. 


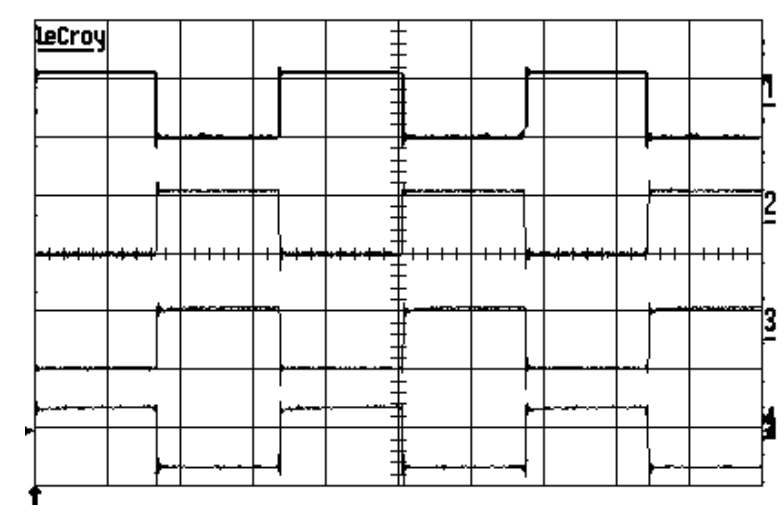

at $+20^{\circ} \mathrm{C}$

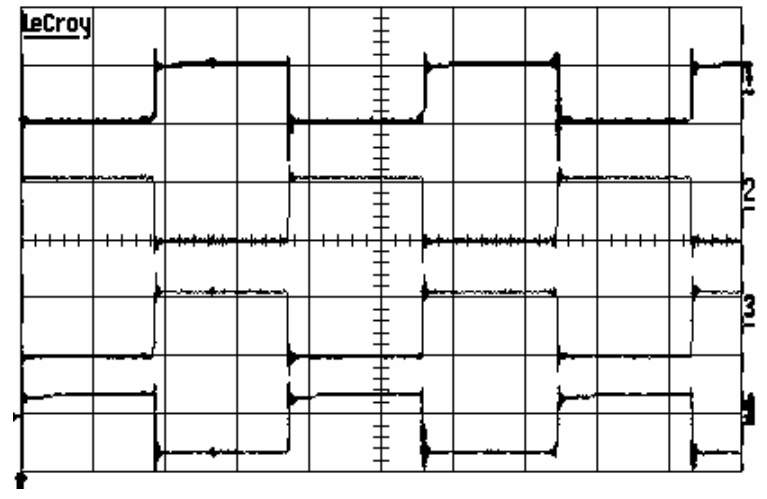

at $-195^{\circ} \mathrm{C}$

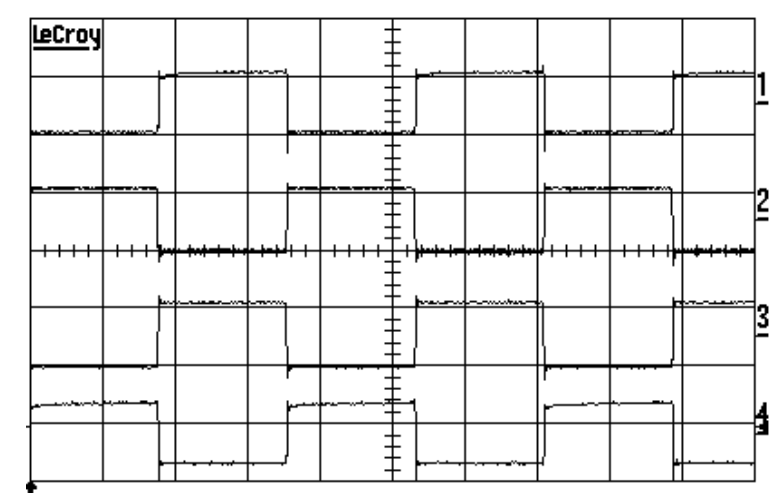

at $+85^{\circ} \mathrm{C}$

Figure 6. Waveforms of the driver output signals GHR (1), GLR (2), GHL (3), and GLL (4) at various temperatures.

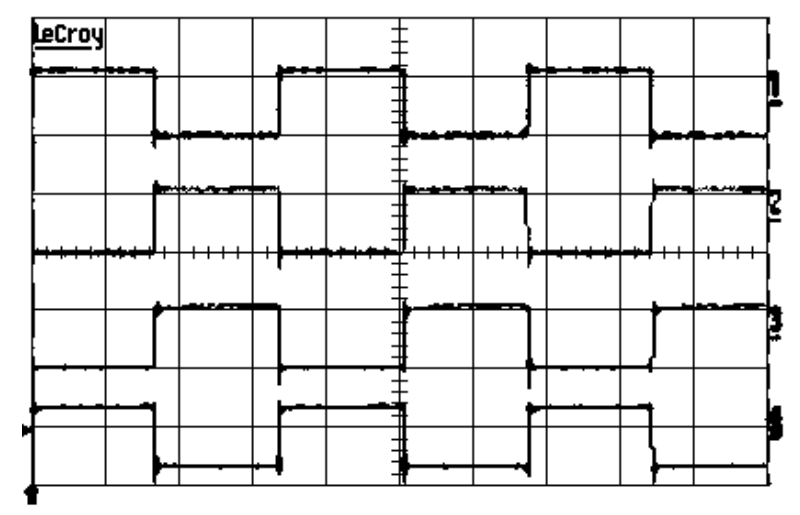

Pre-cycling at $+20^{\circ} \mathrm{C}$

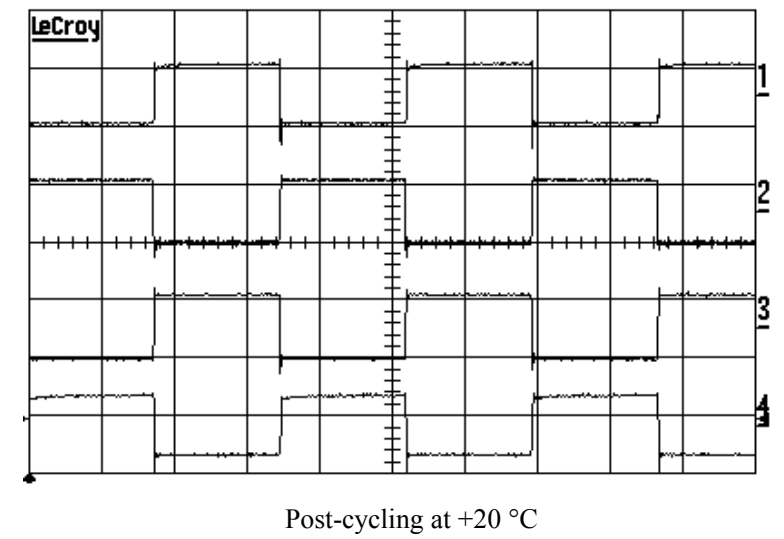

Figure 7. Waveforms of the driver output signals GHR (1), GLR (2), GHL (3), and GLL (4) at $+20^{\circ} \mathrm{C}$.

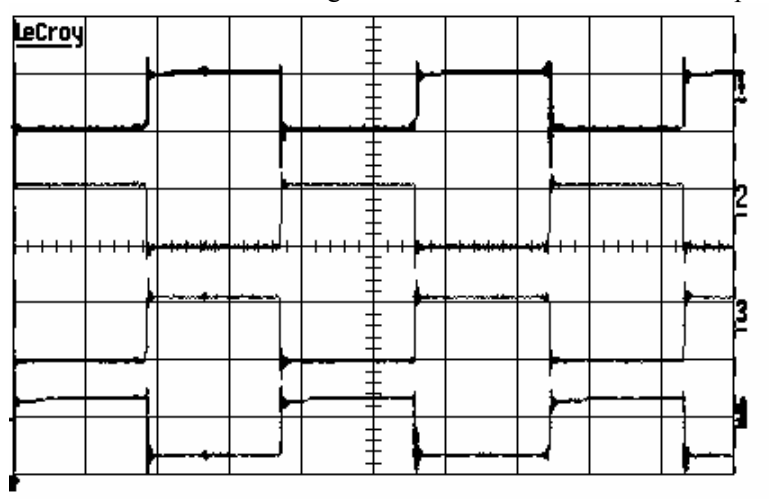

Pre-cycling at $-195^{\circ} \mathrm{C}$

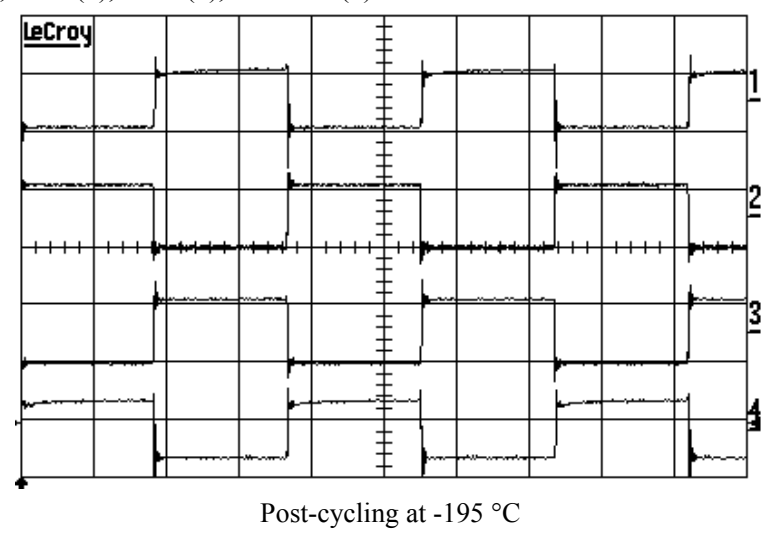

Post-cycling at $-195^{\circ} \mathrm{C}$

Figure 8. Waveforms of the driver output signals GHR (1), GLR (2), GHL (3), and GLL (4) at $-195^{\circ} \mathrm{C}$. 


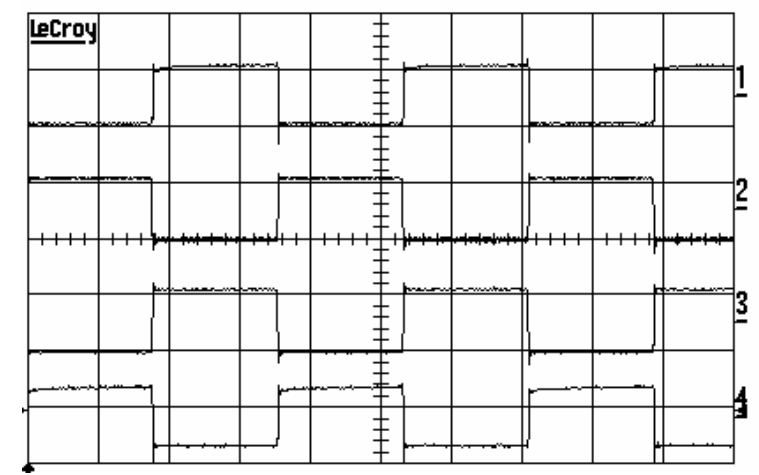

Pre-cycling at $+85^{\circ} \mathrm{C}$

Figure 9. Waveforms of the driver output signals GHR (1), GLR (2), GHL (3), and GLL (4) at $+85^{\circ} \mathrm{C}$.

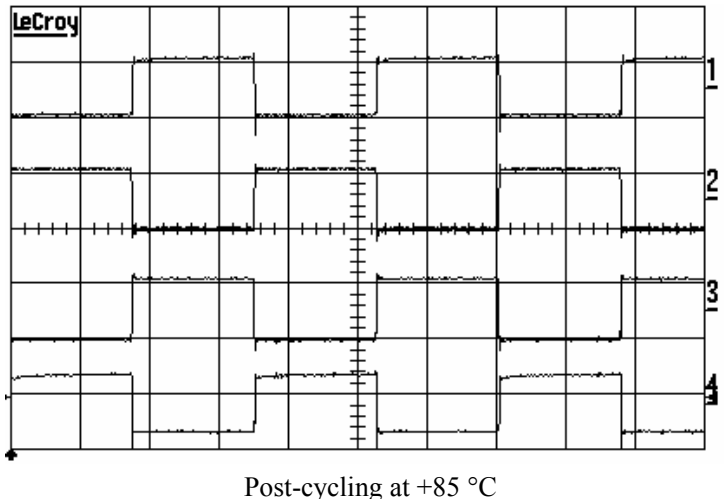

Post-cycling at $+85^{\circ} \mathrm{C}$
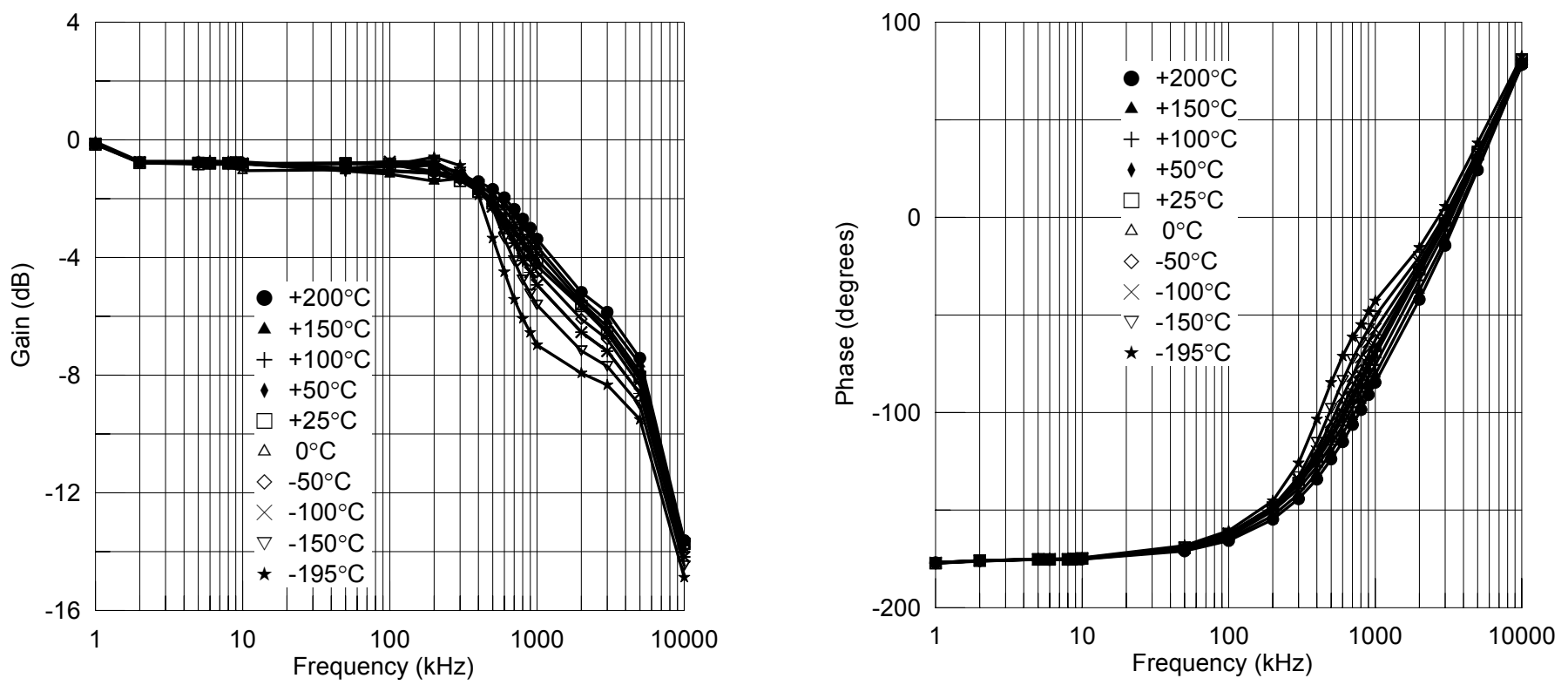

Figure 10. Gain \& phase versus frequency at various temperatures prior to thermal cycling.
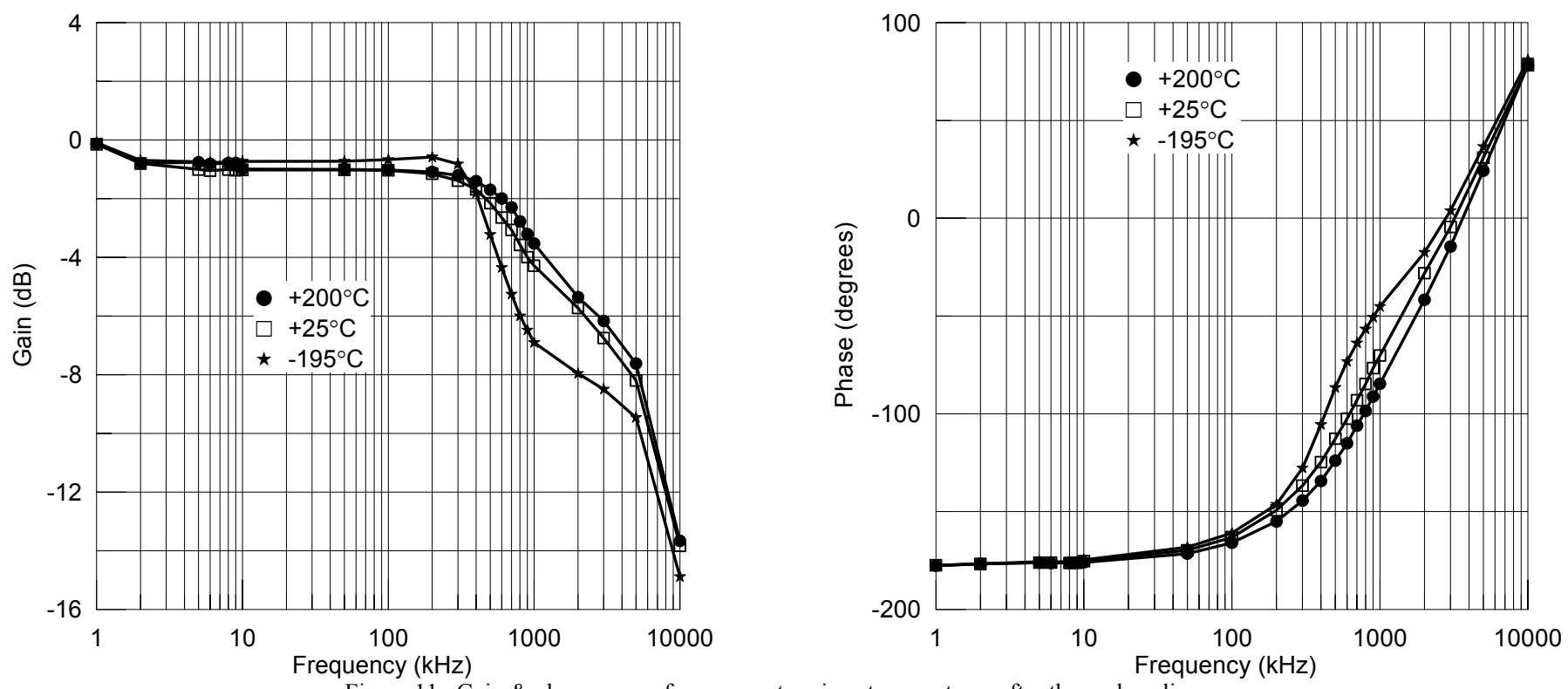

Figure 11. Gain \& phase versus frequency at various temperatures after thermal cycling. 